\section{Use and Disposal of Uranyl Acetate in the Electron Microscope Laboratory: Glow in the Dark or Walk in the Park?}

\author{
Randy Tindall \\ University of Missouri \\ Tindallr@missouri.edu
}

Let's face it-uranyl acetate is the perennial bad boy of chemicals, at least from the standpoint of disposal. A necessary evil in the electron microscopy laboratory, it presents a quandary for those trying to comply with hazardous materials regulations, an effort complicated by its nominal radioactivity. Disposal costs of radioactive materials can be daunting. A past posting to the Microscopy Society of America listserver gave an estimate of US\$7000 per liter and local follow up indicated that, although probably high, that may not be an unreasonable figure (1). In these times of diminished subsidies and expectations of increased cost recovery by academic service facilities like ours, this is of paramount concern.

The Electron Microscopy Core Facility at the University of Missouri-Columbia follows guidelines issued by our campus Environmental Health and Safety (EHS) office regarding hazardous materials and their disposal. Over the past five years, directives regarding uranyl acetate (UA) have run the gamut from pouring it down the drain with lots of water, to collecting it in a common waste container with other fixatives and buffers, to collecting it separately and bagging all utensils that have been in contact with it for pickup as radioactive waste, and back to pouring it down the drain. Our tale is not a unique one. I once worked in an EM lab that was told that UA could be used, but could not be accumulated, could not be poured down the drain, and would not be picked up by the campus EHS office.

Searching for information on the real hazards of UA reveals the nature of the problem. Much of the ample information available is anecdotal and often contradictory. Material Safety Data Sheets (MSDS) routinely describe the chemical as "very toxic" by ingestion or inhalation as dust and "toxic" by contact with cut or abraded skin. Warnings of cumulative radiation effects are given, although it is sometimes (rarely) noted that the very low level of activity of this substance $(10,400 \mathrm{~Bq} / \mathrm{gm}$ or $0.51 \mu \mathrm{Ci} / \mathrm{gm})$ is not harmful as long as the material is not ingested. Over the years, the MSA listserver has received postings ranging from dire warnings of UA as an underestimated radioactive hazard, to dismissal of the risk as trivial.

According to our EHS office, UA in these extremely small quantities is not regulated by the Nuclear Regulatory Commission (NRC) or the Environmental Protection Agency (EPA) (1). Indeed, searching the NRC's website found mention only of transport of more than $100 \mathrm{lbs}$. of UA per shipment as being subject to regulation.

In terms of overall toxicity, UA is described as a suspected or known carcinogen (all MSDS's I have seen) - or not. Consider the surprising (to me) statement, "No human cancer of any kind has ever been seen as a result of exposure to natural or depleted uranium" (2). (Also see the National Risk Characterization Data at http://www.scorecard.org/chemical-profiles/national-riskcharacterization.tcl?edf_substance_id $=541 \% 2 \mathrm{~d} 09 \% 2 \mathrm{~d} 3$ with re- gard to carcinogenicity.) The Indiana Relative Chemical Hazard Ranking System (IRCH, formerly known as 3P2M) assigns UA a Total Hazard Score of 8 out of 200, a Worker Exposure Hazard Score of 8 out of 50, and an Environmental Hazard Value Score of 26 out of 100 , putting it in their lowest risk category. Compare these values to scores of 10,18 , and 3 respectively, for dibasic sodium phosphate, a component of phosphate buffers generally considered as essentially harmless. (Go to http://www.scorecard.org/chemicalprofiles/summary.tcl?edf_substance_id $=541-09-3$ for details of rankings and how they are derived).

It is generally agreed in the literature that the heavy metal toxicity of UA outweighs its radiation dangers. For an excellent comprehensive review of the studied health effects of uranium, see Canada's Healthy Environments and Consumer Safety website (3). A key issue with UA as a uranium source is its ready solubility in water, which means that uranium can be easily absorbed through the intestine if ingested (4). On the plus side, it may also mean that inhaled UA dust does not accumulate in the lungs, but should dissolve and be transported to other organs or excreted.

Its health effects appear to be related primarily, but not exclusively, to disorders of the kidney, if ingested in sufficient quantities $(4,5)$. About $95 \%$ of uranium accumulation in the body is in the skeleton(4), and it has been estimated that the equilibrium content in bone is about 11 days normal accumulation, which is around $1.3-1.5 \mu \mathrm{g} /$ day from food and drinking water $(4,6)$, depending upon location and other factors. A mean of about $1 \%$ of ingested uranium is actually taken up by the system (7). Remember that UA is quite soluble, so the percentage may be higher for this compound, and most of this would be relatively quickly excreted, while most of the rest would end up in bone.

UA's $\mathrm{LD}_{50}$ at 14 days in rats and mice is $204 \mathrm{mg} / \mathrm{kg}$ body weight and $242 \mathrm{mg} / \mathrm{kg}$ respectively for oral ingestion, and $8.3 \mathrm{mg} / \mathrm{kg}$ and $20.4 \mathrm{mg} / \mathrm{kg}$ for subcutaneous injection (8). By way of comparison, if a person weighing 70 kilograms stained 100 grids per day in 20 $\mu \mathrm{l}$ drops of $3 \% \mathrm{UA}$ and somehow managed to ingest each and every drop, that person would receive a daily UA exposure of about 0.89 $\mathrm{mg} / \mathrm{kg}$ of body weight or $12.04 \mathrm{mg} / \mathrm{kg}$ over 14 days, or less than $6.0 \%$ of the 14 -day $\mathrm{LD}_{50}$ for rats. (I'll let somebody else do the math for en bloc staining.) Obviously, this does NOT mean that these much lower doses might not be damaging to one's health, since damage to the proximal tubules of the kidney and other effects on renal function can occur, mostly in kidneys with more than $1 \mathrm{mg} / \mathrm{kg}$ of UA (4). The point is that with even the most minimal precautions (like avoiding deliberate ingestion!), absorption of UA by workers in the EM laboratory would be vanishingly low-and no argument is being made here for merely minimal precautions.

So, what standards might be reasonable for dealing with this maverick chemical? For starters, it might be a good idea to get beyond that mile-high radioactive warning label, which seems to be the source of the regulatory confusion. Treating UA as a significant radioactive hazard is almost certainly overkill, weighing the cost of shipping and disposal against the health risks, if any, due to radiation. Additionally, it may be argued that the miniscule radiation hazard it poses is only increased by accumulating used UA in larger quantities or by evaporating it to powder to reduce volume. Indeed, the tiny amounts used at any one time in the typical EM lab would seem to make disposal with lots of water down 
the drain a reasonable option. However, as with lead citrate, heavy metal toxicity may be of concern in an environmental release. In this case, collection in a common container with other fixatives and reagents would seem to make sense at first glance, resulting in dilution and more frequent pickup. But in the arcane world of hazardous materials management things are rarely so simple. Because the State of Missouri has not adopted rules promulgated at the Federal level, mixing UA with other EPA-regulated chemicals qualifies the batch as "mixed waste", even though the UA has already been determined to be effectively non-hazardous in terms of its disposal. Such mixed wastes are disposed of here by a vendor at a cost of $\$ 2890$ per 30-gallon drum, regardless of the actual amount in the drum (mandated time limits on holding the waste often mean that incompletely filled drums have to be disposed of). Costs can be MUCH higher (upwards of $\$ 20-30,000$ ) if that mixed waste contains certain other elements, such as cadmium (1). In addition, because Missouri did not adopt regulatory relief, on this campus methanolic UA counts as a mixed waste. Can we evaporate the methanol in a fume hood and remix the UA with water for disposal? No! That is a violation of the Clean Air Act and the Resource Conservation and Recovery Act, which establishes the rules regarding hazardous wastes.

So, the options at our location are disposal down the drain with copious amounts of water, or segregating UA for pick up by EHS and letting them dispose of it through contracted vendors.

In terms of handling UA, precautions used with any hazardous material should be taken, especially avoiding skin contact, inhalation, and ingestion. Use of gloves when handling solutions and of masks and/or fume hoods when handling the powder are eminently sensible things to do. Minor spills should be wiped up immediately to avoid evaporation to a powder which can be inhaled if airborne. Pipettes, paper towels, Petri dishes, and other materials having contacted UA might be bagged, again to prevent evaporation and dust and to avoid exposure by custodial staff, who are not normally paid or trained to work with toxics, as lab workers are. Normal disposal in the trash could follow, taking care to observe regulations involving disposal of such things as syringes and sharps. Erring on the side of caution and avoiding proximity to UA and any hazardous substance during pregnancy would be reasonable. And stop eating UA-right now!

The handling and disposal of UA is a "hot" topic for debate. This article is intended as a starting point for such a discussion and certainly not as an exhaustively researched final word on the issue. No attempt is being made to portray UA as harmless or non-toxic, by any means, but only to put its health and environmental hazards in perspective. This brief review of the topic might indicate that UA may be one of the more benign substances we deal with EM labs, but it must be remembered that our labs are as safe as they are because of a certain amount of healthy paranoia. "Healthy paranoia" and "hysteria," however, are not synonymous.

It should be emphasized that all local regulations for handling UA should be followed to ensure compliance with the law, but a dialogue on what these regulations should be is certainly in order, with full knowledge that changing them may be a Herculean task. Constantly shifting rules and sometimes prohibitively costly, and probably unnecessary, disposal as a radioactive compound argue for making the effort.

\section{Acknowledgements}

I would like to express my appreciation to Roger Giles, Manager of Hazardous Materials-Field Operations, Todd Houts, Assistant Director, and Tanya Haeussler, Sr. Environmental Health Technician of the University of Missouri at Columbia Environmental Health and Safety Office for their information and comments on this article.

\section{References}

(1) Personal communication: Roger Giles, Manager of Hazardous Materials-Field Operations, Environmental Health and Safety, University of Missouri, Columbia, Missouri.

(2) Public Health Statement for Uranium. Summary Chapter of the Toxicological Profile for Uranium. Agency for Toxic Substances and Disease Registry, U.S. Department of Health and Human Services, Atlanta, Georgia. Sept. 1999.

(3) Uranium. In: Water Quality and Health Bureau. Healthy Environments and Consumer Safety. Health Canada. Ottawa, Ontario, Canada. October, 1999.(http: //www.hc-sc.gc.ca/hecssesc/water/publications/uranium/chapter4,htm)

(4) Berlin, M. and Rudell, B. Uranium. In: Handbook on the toxicology of metals $2^{\text {nd }}$ edition. L. Griberg, G.F. Nordberg and V.B. Vouk (eds). Elsevier Science Publishers, Amsterdam, Pp. 623-637 (1986).

(5) Leggett, R.W. The behaviour and chemical toxicity of U in the kidney: a reassessment. Health Phys., 57(3): 365-383 (1989).

(6) Wrenn, M.E., Durbin, P.W., Howard, B., Lipsztein, J., Rundo, J., Still. E.T., and Willis, D.L. Metabolism of ingested $U$ and Ra. Health Phys, 48(5): $601-633$ (1985).

(7) Tracy, B.L. and Limson Zamora, M. Absorbed fraction of uranium in humans. Poster presentation, 39th Annual Meeting of the Health Physics Society, San Francisco, CA, June 26-30 (1994). Cited in "Uranium." Water Quality and Health Bureau. Healthy Environments and Consumer Safety. Health Canada. Ottawa, Ontario, Canada. October, 1999.

(8) Domingo, J.L., Llobet, J.M., Tomas. J.M., and Corbella, J. Acute toxicity of uranium in rats and mice. Bull. Environ. Contam. Toxicol., 39: 168-174 (1987).

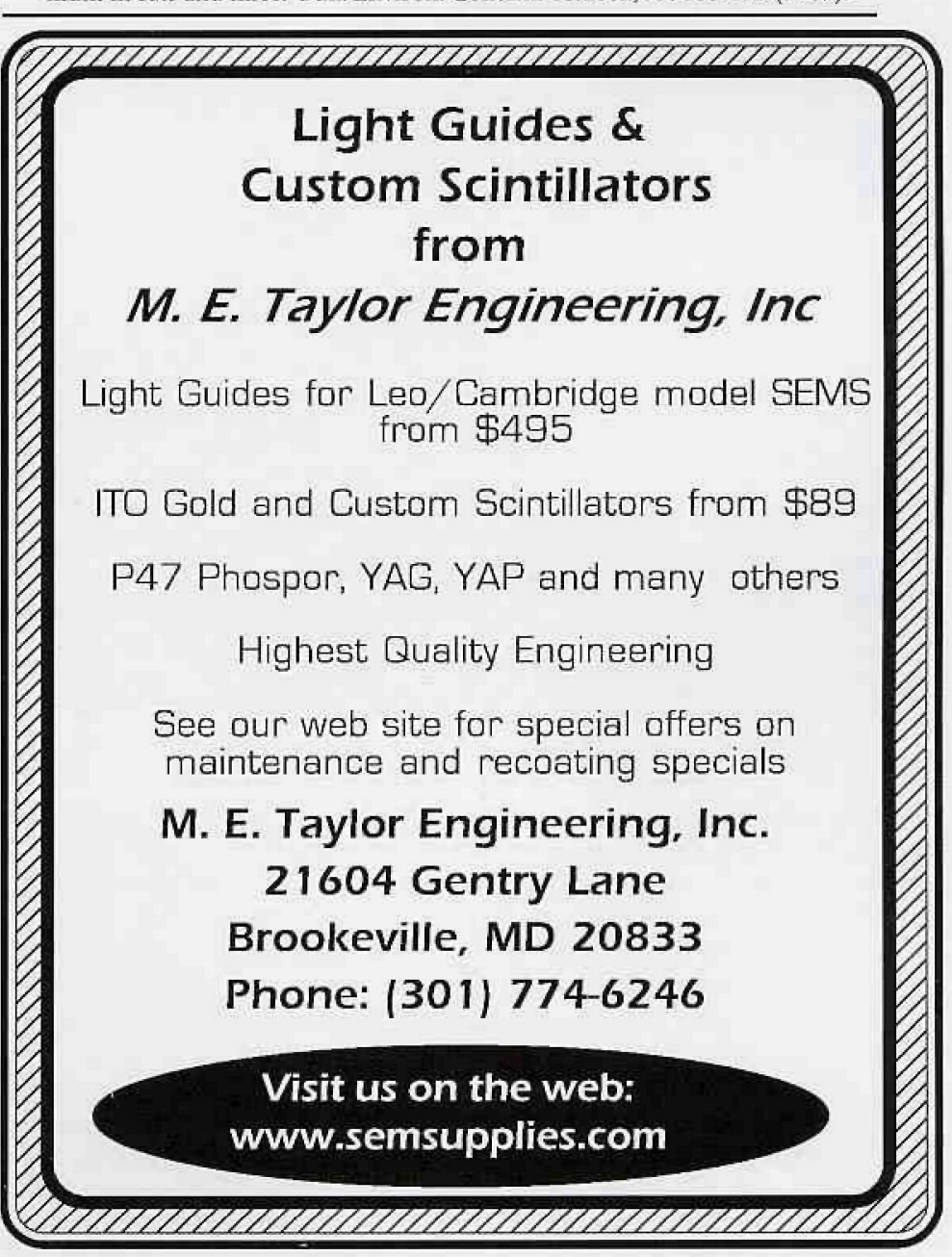

